\title{
Effect of Width of Gas/Liquid/Solid Three-Phase Boundary Zone of Discrete Water Film on Atmospheric Corrosion of Metals
}

\author{
Jia Wang ${ }^{*}, 1,2$ and Jing Jiang ${ }^{1}$ \\ ${ }^{1}$ Ocean University of China, Qingdao 266100, China \\ ${ }^{2}$ State Key Laboratory for Corrosion and Protection of Metals, Shenyang 110016, China
}

\begin{abstract}
The influence of potential on contact angle and the effect of TPB width on the cathodic corrosion processes of metals were studied by steady polarization and EIS technique combined with contact angle measurement. It is found that both cathodic limiting current density and corrosion current density linearly increases with increasing the TPB width, confirming the important role of TPB width in gas/liquid/solid multiphase corrosion systems. Based on above results, the effect of water film thickness on atmospheric corrosion rate was quantitatively evaluated by the TPB width.
\end{abstract}

Keywords: Gas/liquid/solid three-phase boundary zone, TPB width, water film thickness, contact angle, atmospheric corrosion.

\section{INTRODUCTION}

Study of corrosion behavior of metals in gas/liquid/solid multiphase corrosion systems, such as atmosphere, ocean splash zone, soil and reinforced concrete, has received increasing interest in recent years. Liquid state on metal surfaces is an important factor influencing the corrosion process since the corrosive composition in gas and solid can affect the corrosion process only through liquid. In general, the contact angle formed by liquid in contact with metal is smaller than $90^{\circ}$ due to the better wettability of metal by aqueous electrolyte in these systems. On this condition, the electrochemical reaction zone under the liquid layer can be divided into a bulk zone and a three-phase boundary (TPB) zone. The term TPB zone used in this paper is defined as a two-dimensional liquid zone immediately inside TPB with the water film thickness $(\delta)$ ranging from 0 to $100 \mu \mathrm{m}$. Similarly, the term bulk zone is defined as a twodimensional liquid zone in which $\delta$ is greater than $100 \mu \mathrm{m}$.

It is generally agreed that the thickness of static diffusion layer is about $100 \mu \mathrm{m}$. If $\delta$ exceeds $100 \mu \mathrm{m}$ (in bulk zone), the diffusion rate of oxygen is similar to that in solution, independent of $\delta$. If $\delta$ ranges from 0 to $100 \mu \mathrm{m}$ (in TPB zone), the diffusion rate of oxygen first increases and then decreases with a reduction in $\delta[1-3]$, but the average rate is still higher than that in bulk solution, indicating that the TPB zone plays a more important role in the cathodic oxygen reduction process than bulk zone. Therefore liquid state affects cathodic process mainly by influencing the geometric properties of TPB zone (e.g. its length and width). The studies of effect of TPB length and width on cathode and corrosion processes can reveal the important role of liquid state in gas/liquid/solid multiphase corrosion systems.

Experimental and modeling studies of TPB length effects on cathode and corrosion processes of metals has been

*Address correspondence to this author at the Ocean University of China, Qingdao 266100, China; Tel/Fax: +86 532 66781903;

E-mail: jwang@mail.ouc.edu.cn published [4-12]. The effect of TPB width on cathode and corrosion behavior will be investigated in this paper.

Fig. (1) showed the TPB zone and length of TPB zone [4]. Based on the definition of TPB width proposed in ref. [4], w can be expressed as

$w=100 \mu m \cdot \operatorname{ctg} \theta$

where $\theta$ is liquid-metal contact angle and $100 \mu \mathrm{m}$ is the thickness of static diffusion layer. Based on (Eq. 1), w only depends on the value of $\theta$ and can be determined by contact angle measurement. There are three kinds of systems formed by different experiment methods designed in this paper: in case 1 , a vertical electrode was under partial immersion in electrolyte; in case 2, an electrolyte droplet was attached on planar electrode surfaces; in case 3, a post-tilt electrode was under partial imersion in electrolyte. The schematic diagrams of $\mathrm{w}$ and $\theta$ are shown in Fig. (2), respectively.

It is known that electrocapillary action at the TPB zone (e.g. the rise or descent of solution meniscus and the corresponding contact angle variations) is strongly dependent on the polarization potential of studying electrode, indicating the dependence of TPB width on potential. Thus it is necessary to study the effect of potential on contact angle variations before clarifying the relationship between the cathodic oxygen reduction process and the TPB width.

In the field of corrosion science, little work has been done on the influence of TPB width on the corrosion behavior of metals. The objective of this paper are, first, to clarify the effect of potential on TPB width, second, to investigate the effect of TPB width on cathode and corrosion processes of metals, and finally, to evaluate the role of TPB width in atmospheric corrosion systems.

\section{EXPERIMENTAL}

Experiment was divided into two parts. Experiment I: Studies of effect of potential on contact angle which were performed by steady polarization measurement combined with contact angle measurement in the systems formed either 


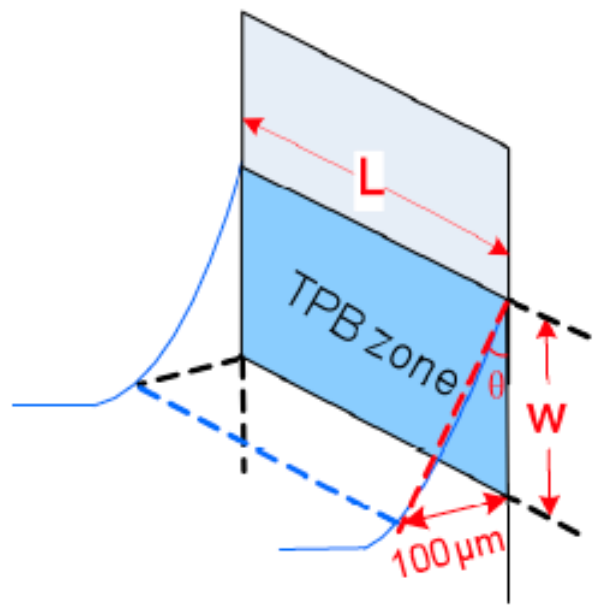

(a)

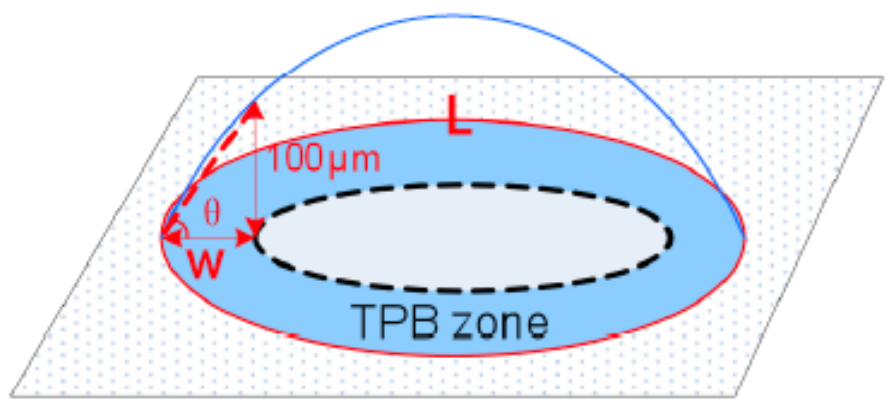

(b)

Fig. (1). The schematic diagram of the geometry of TPB zone. (a) A vertical electrode under partial immersion in electrolyte and (b) an electrolyte droplet attached on a planar electrode surface [5].

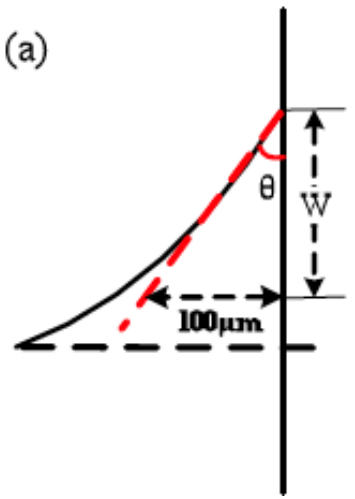

(b)

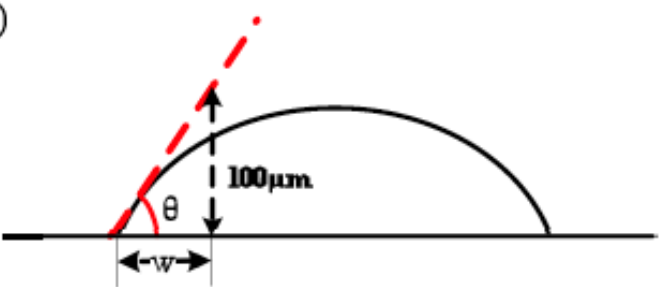

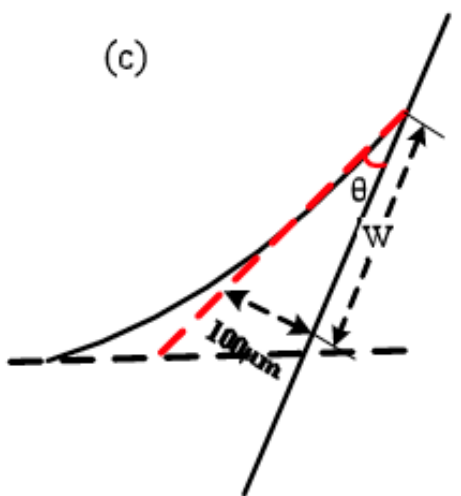

Fig. (2). The schematic diagram of TPB width and contact angle. (a) a vertical electrode under partial immersion in electrolyte; (b) an electrolyte attached on planar electrode surfaces; (c) a post-tilt electrode under partial immersion in electrolyte.

by a vertical metal plate electrode under partial immersion in electrolyte (Case 1) or by an electrolyte droplet attached on planar electrode surfaces (Case 2). Experiment II : Studies of effect of TPB width on cathode and corrosion process of metals which were performed by steady polarization measurement and impedance measurement combined with contact angle measurement in the system formed by a posttilt electrode under partial immersion in electrolyte (Case 3).

Specimens used in Experiment I and II were both prepared from a sheet of $\mathrm{A} 3$ carbon steel with the working area of $10 \times 20 \times 2 \mathrm{~mm}^{3}$. The chemical composition of A3 mild steels was listed in Table 1. Prior each experiment, the working area was finally wet-ground with 1000 grade emery papers, washed in de-ionized water, degreased with alcohol, and then dried with warm air. The electrolyte is $0.1 \mathrm{M} \mathrm{NaCl}$ solution, prepared from the analytical grade chemical reagent and de-ionized water.

Table 1. Chemical Composition of A3 Mild Steels

\subsection{Experiment I: Studies of Effect of Potential on Contact Angle}

In the first system, a three-electrode cell was used with a saturated calomel electrode (SCE) as reference electrode which was connected with the electrolyte using a lugging capillary and a platinum leaf immersed into the electrolyte as counter electrode (Fig.3a). In the second system, a twoelectrode cell was used in which two identical A3 carbon steel metal plates were parallelly embedded in epoxy resin and separated with mylar as the insulated gap (Fig.3b). A certain volume of electrolyte was dropped onto the intersection of two electrodes using a micropipette. To avoid the evaporation of droplet, the cell was placed inside a humidity-temperature controlled chamber to keep the humidity at $85 \% \mathrm{RH}$ and the temperature at $20^{\circ} \mathrm{C} \pm 2^{\circ} \mathrm{C}$.

Steady polarization tests were done potentiostatically from the open circuit potential $\left(\mathrm{E}_{\mathrm{ocp}}\right)$ to $-1.0 \mathrm{~V} / \mathrm{SCE}$ at an

\begin{tabular}{|c|c|c|c|c|c|c|c|c|c|}
\hline Chemical Composition & $\mathbf{C}$ & $\mathbf{S i}$ & $\mathbf{M n}$ & $\mathbf{P}$ & $\mathbf{S}$ & $\mathbf{C r}$ & $\mathbf{N i}$ & $\mathbf{A l}$ & $\mathbf{C u}$ \\
\hline \hline Mass \% & 0.06 & 0.30 & 0.50 & 0.45 & 0.30 & 0.025 & 0.30 & 0.015 & 0.035 \\
\hline
\end{tabular}


(a)

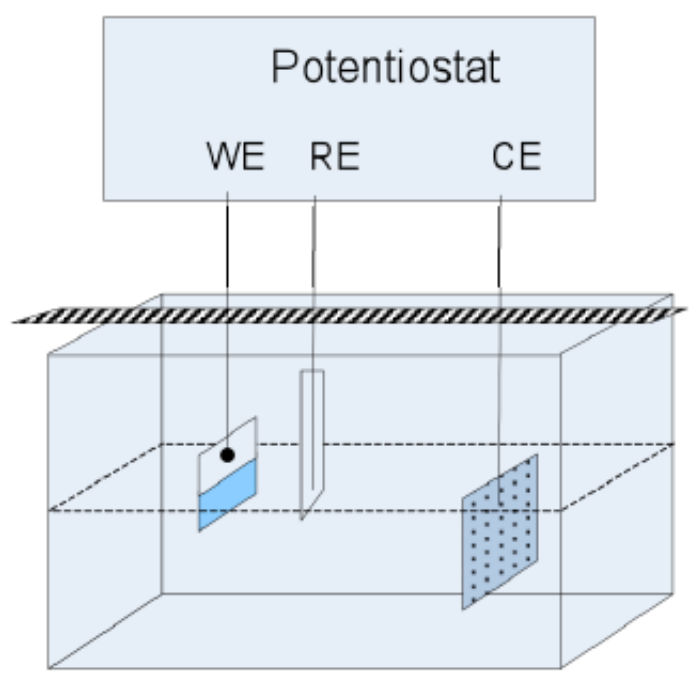

(b)

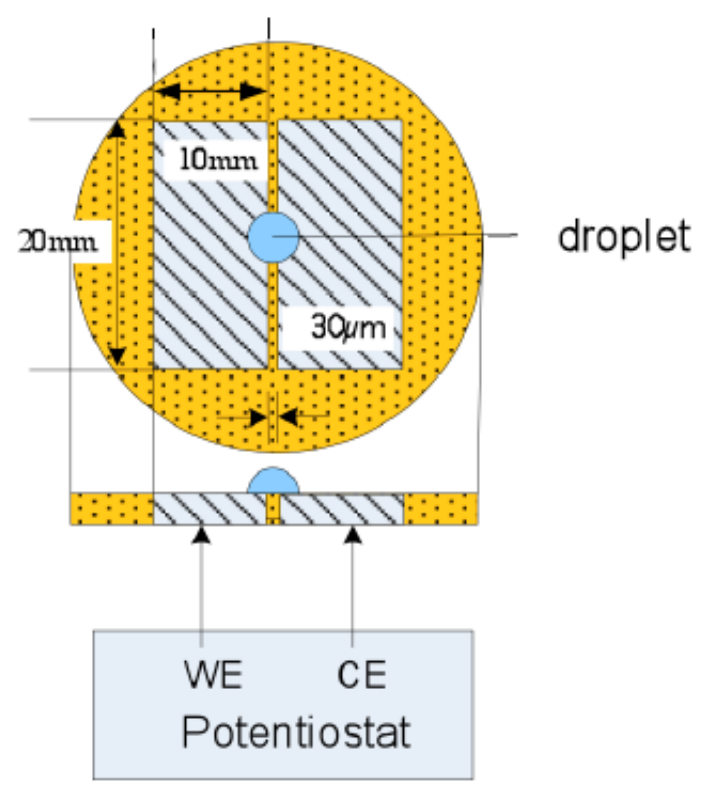

(c)

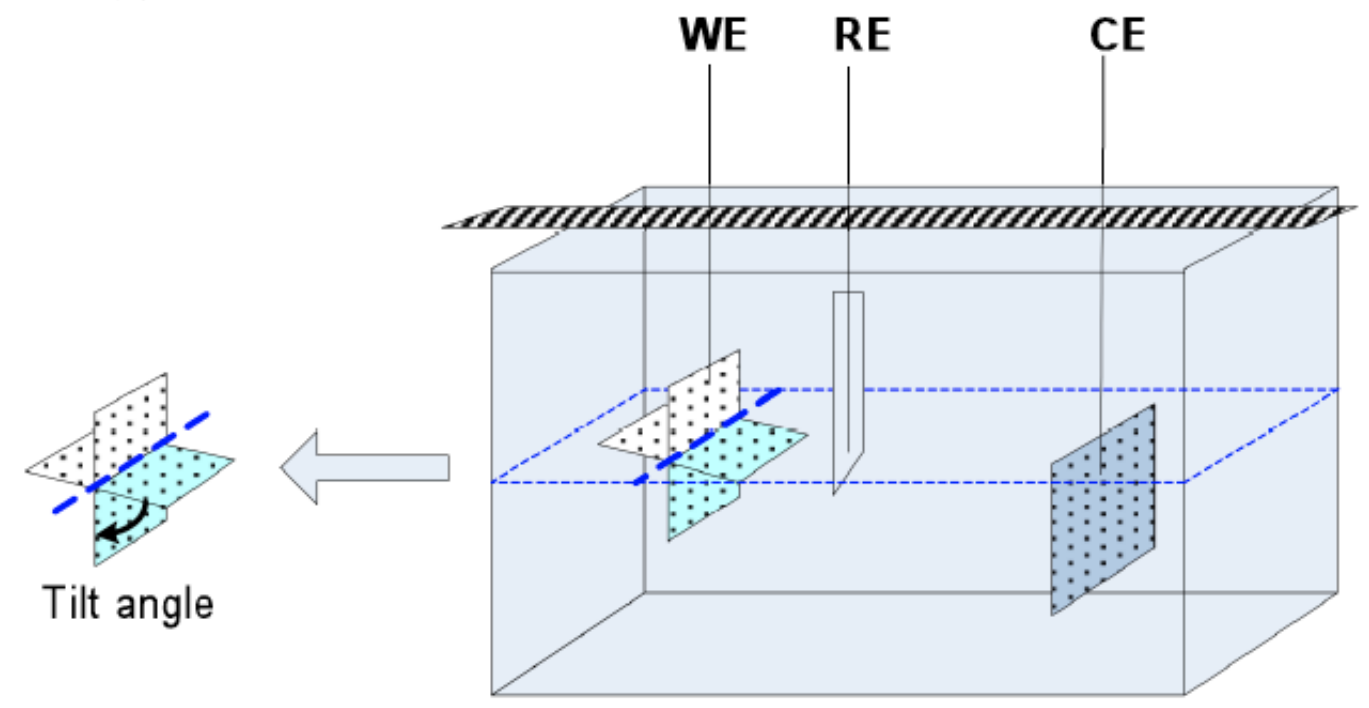

Fig. (3). The schematic diagram of cell for steady polarization tests combined with contact angle measurements. In which, WE, RE and CE refer to working electrode, reference electrode and counter electrode, respectively. The tilt angle changed form $10^{\circ} \sim 90^{\circ}$. (a) a threeelectrode cell used for a vertical electrode under partial immersion in electrolyte [5]; (b) a two-electrode cell embedded in circle epoxy bed used for an electrolyte attached on planar electrode surfaces; (c) a three-electrode cell used for a post-tilt electrode under partial immersion in electrolyte.

interval of $50 \mathrm{mV}$ (in the first case) and from 0 to $1.0 \mathrm{~V}$ at an interval of $100 \mathrm{mV}$ (in the second case) by using a potentiostat galvanostat (PAR273A, America). The $\mathrm{E}_{\text {ocp }}$ was obtained by partially submerging the electrode into the electrolyte for $1 \mathrm{~h}$ before each test. The contact angle was photoed with a DIGITAL CCD CAMERA (Pixera, America) after polarizing 1 minute at each potential and determined by measuring the tangent to the gas/electrolyte interface at its intersection with the metal surface using software Adobe Photoshop 7.0 (Fig. 2a, b). Meanwhile, micro-liquid state around the TPB zone was recorded by using a highmagnification microscope (Pixera, America).

\subsection{Experiment II: Studies of Effect of TPB Width on Cathode and Corrosion Processes of Metals}

The effect of TPB width on cathode and corrosion process of metals was studied by using a partially immersed post-tilt A3 steel electrode with different tilt angles. Different values of w were determined by measuring contact angles at different electrode-tilt angles. A three-electrode cell was used in this part (Fig. 3c): the working electrode tiltedly installed on a Plexiglas frame to make the working area partially immerse into the electrolyte, a SCE and a platinum leaf used as reference electrode and counter electrode, respectively. 
Steady polarization tests were done potentiostatically from $\mathrm{E}_{\text {ocp }}$ to $-1.0 \mathrm{~V} / \mathrm{SCE}$ at an interval of $50 \mathrm{mV}$ by using a potentiostatlgalvanostat (PAR273A, America). The current was recorded and the contact angle was recorded after polarizing 1 minute at each potential. The determination of contact angle was similar to that in Experiment I, and the schematic diagram was shown in Fig. (2c).

The impedance measurements were carried out using a signal with AC amplitude of $10 \mathrm{mV}$ and a frequency range of $99 \mathrm{kHz}-9 \mathrm{MHz}$. The polarization resistance $\left(\mathrm{R}_{\mathrm{p}}\right)$, derived from the EIS, is inversely proportional to the corrosion rate of metals. The $R_{p}$ was also evaluated by running linear polarization resistance (LPR) curves, which were obtained by polarizing the electrode from -20 to $+20 \mathrm{mV}$ with respect to the $\mathrm{E}_{\text {corr }}$ at a scan rate of $0.166 \mathrm{mV} / \mathrm{s}$. EIS and LPR curves were both made using a PARSTAT 2263 (Prinston, America). The software ZView2 and CView2 were used for the data analysis. The test devices are shown in Fig. (4).

\section{RESULTS AND DISCUSSION}

\subsection{Effect of Potential on TPB Width}

It is known that TPB width is strongly dependent on liquid-metal contact angle. In the case of a vertical electrode under partial immersion in electrolyte, it was clearly observed the rise of solution meniscus during cathodic polarization in different combinations of metal (such as A3 steel, 304 stainless steel and $\mathrm{Cu}$ ) and $\mathrm{NaCl}$ solution. The contact angle measurement results showed that $\theta$ linearly decreased with increasing the cathodic polarization potential (as Fig.5a), indicating the effect of potential on TPB width. In the case of an electrolyte droplet attached on planar electrode surfaces, the expansion of cathodic area of droplet during cathodic polarization was also observed. Note that the cathodic area is expanding outwards at every moment with increasing the voltage, whereas the anodic area is limited to almost the same region, indicating that the meniscus rise (or liquid expansion) is only associated with the cathodic process, independent of the anodic process. The contact angle measurement results showed a similar linear decrease of $\theta$ with increasing the voltage (as Fig. 5b), in agreement with the tendency shown in Fig. (3a), confirming that the dependence of TPB width on cathodic polarization potential was independent of liquid state on metal surfaces.

The effect of potential on contact angle was described by the Lippmann equation which gave a reasonable explanation for the contact angle variations during cathodic polarization. Here, from another point of view, we propose the theory of formation of micro-droplets on metal surfaces to explain the meniscus rise and contact angle variations during cathodic polarization. The micro-droplets phenomenon occurred in atmospheric environment has been reported and investigated by many authors [5-11]. It is known that when a main-

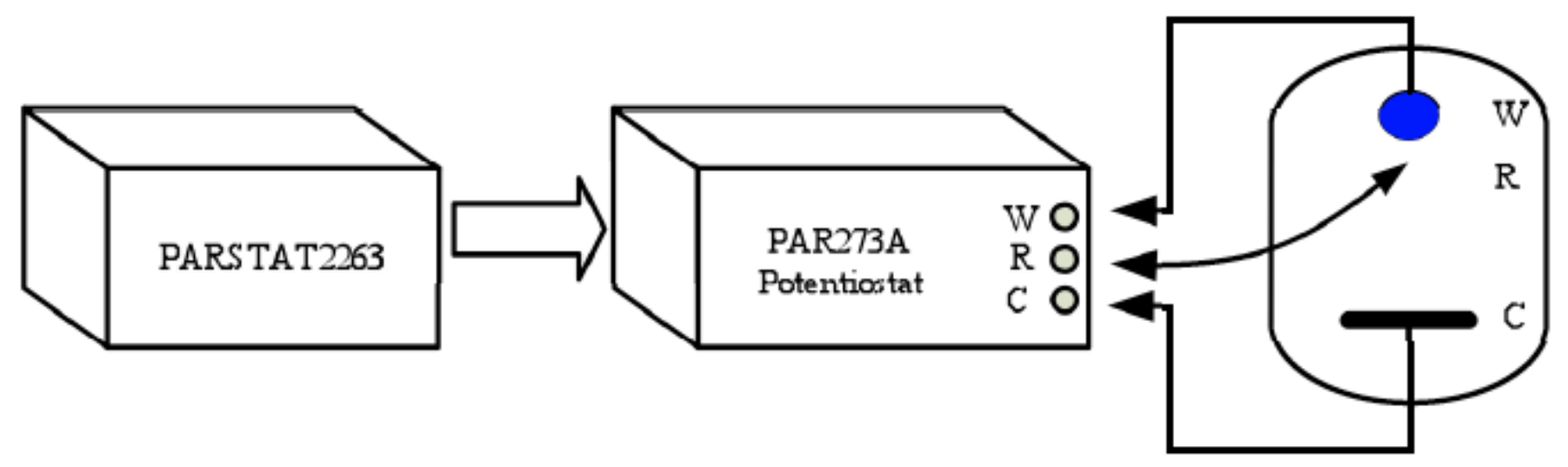

Fig. (4). Schematic of the devices for electrochemical measurements.
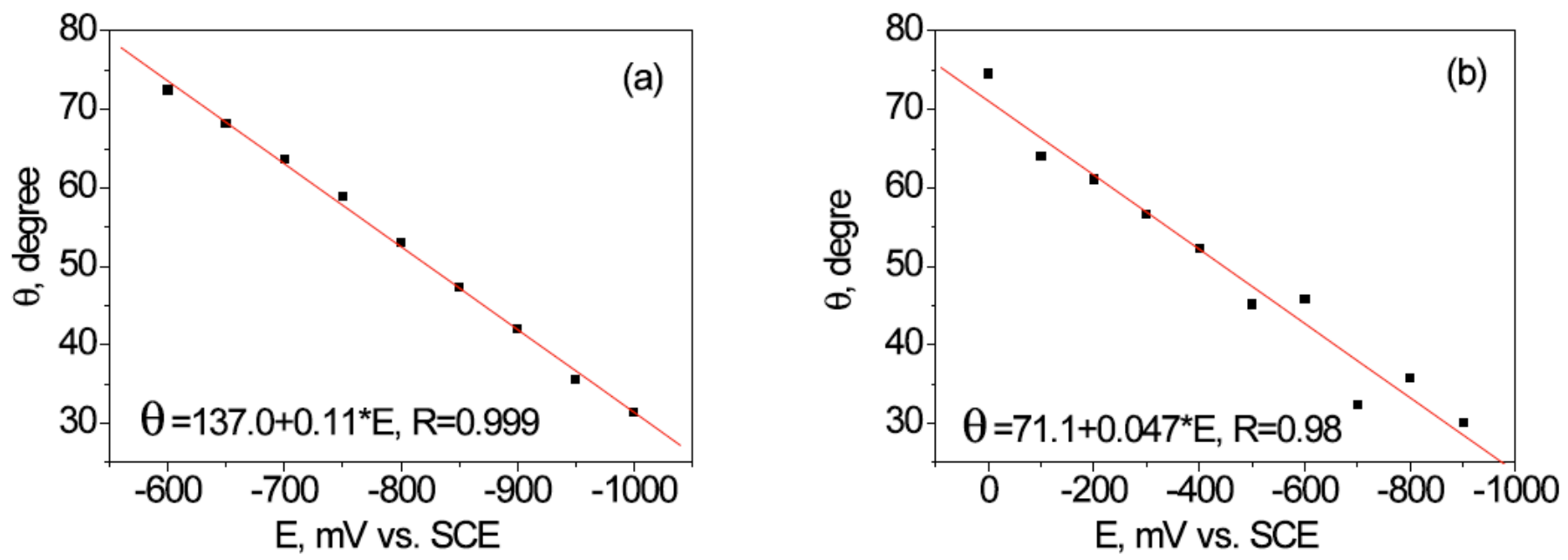

Fig. (5). The contact angle as a function of the cathodic polarization potential. (a) for a vertical A3 steel plate electrode under partial immersion in $0.1 \mathrm{M} \mathrm{NaCl}$ [5]; (b) a $0.1 \mathrm{M} \mathrm{NaCl}$ droplet attached on two electrodes (A3 steel) surfaces. 

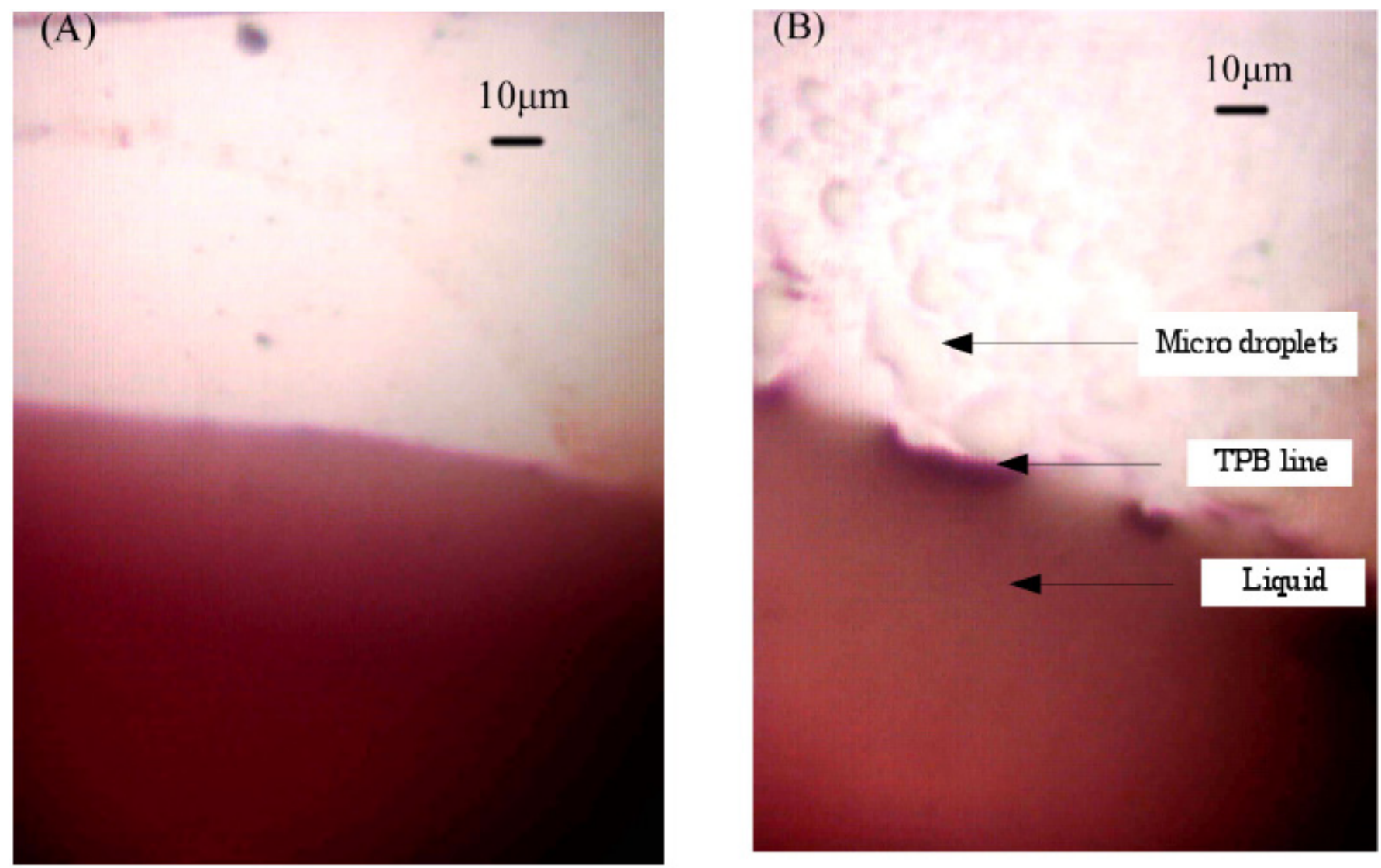

Fig. (6). Micro-droplets formed on a vertical A3 steel plate surface under partial immersion in $0.1 \mathrm{M} \mathrm{NaCl}$ solution. Part of the liquid of $\mathrm{NaCl}$ solution is seen in lower right in each photograph. (A) ocp; (B) 2 minutes after polarizing at $-850 \mathrm{mV} / \mathrm{SCE}$.

droplet of $\mathrm{NaCl}$ solution was placed on a corrosive metal surface, the micro-droplets of $1-10 \mu \mathrm{m}$ in diameter immediately formed and extended around the edge of the main-droplet. In our experiments, the formation of a large amount of micro-droplets around TPB zone during cathodic polarization was also observed with the help of a highmagnification microscope, as shown in Fig. (6).

With increasing the polarization potential and time, micro-droplets continuously grew up, coalesced and finally linked together, causing the rise of solution meniscus and then the decrease of contact angle. Accordingly, the microdroplets phenomenon may be a main reason for the meniscus rise and contact angle variation during cathodic polarization. The results that the primary droplet acted as an anode and the micro-droplets and the wet area became cathodic based on the potential distribution measured by Kelvin probe [6-11], agrees well with the phenomenon that the rise of the solution meniscus and the decrease of contact angle only depend on cathodic process, independent of anodic process.

Note that on condition of $30^{\circ}<\theta<120^{\circ}, \quad \operatorname{ctg} \theta$ is approximately negative linear correlated with $\theta$. The measured values of contact angle in case 1 and 2 are both in the range of $30^{\circ}-70^{\circ}$, satisfying the above linear condition. Accordingly, $\theta$ is negative linear correlated with $\operatorname{ctg} \theta$, and then the linear dependence of $\theta$ on E (Fig. 5) leads to a linear dependence of $\operatorname{ctg} \theta$ on $\mathrm{E}$. Since $\mathrm{w}$ is directly proportional to $\operatorname{ctg} \theta$ based on Eq. (1), a linear increase in w with increasing the cathodic polarization potential is obtained, shown in Fig. (7).

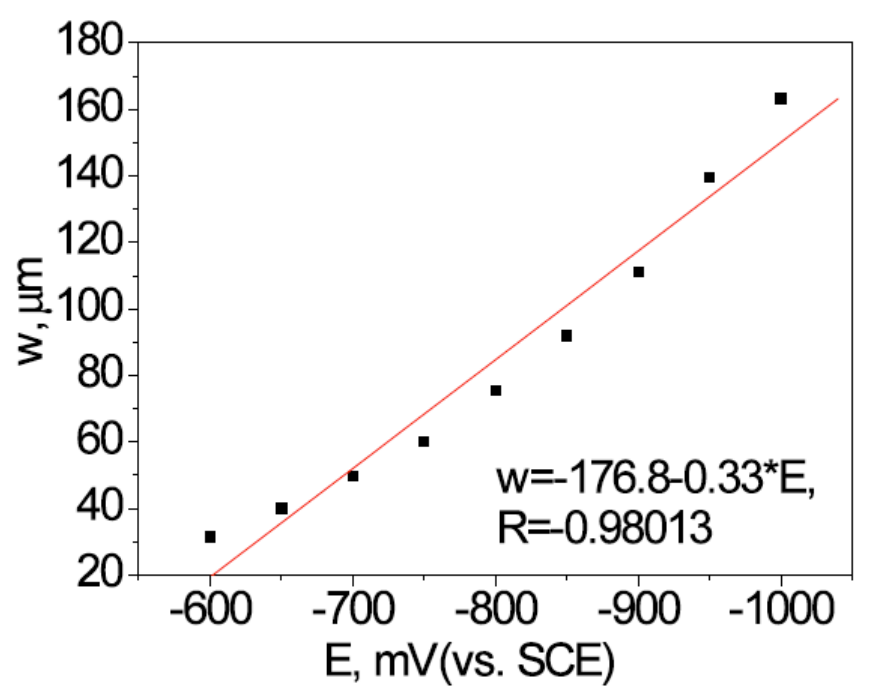

Fig. (7). The TPB width as a function of polarization potential ( $v s$ SCE) for a vertical A3 steel plate electrode under partial immersion in $0.1 \mathrm{M} \mathrm{NaCl}$ [5].

\subsection{Effect of TPB Width on Cathodic Oxygen Reduction Process of Metals}

The cathodic polarization curves of a partially immersed vertical $\mathrm{A} 3$ carbon steel electrode in $0.1 \mathrm{M} \mathrm{NaCl}$ solution as a function of $g$ (TPB length per unit area) have been obtained, shown in Fig. (8). 


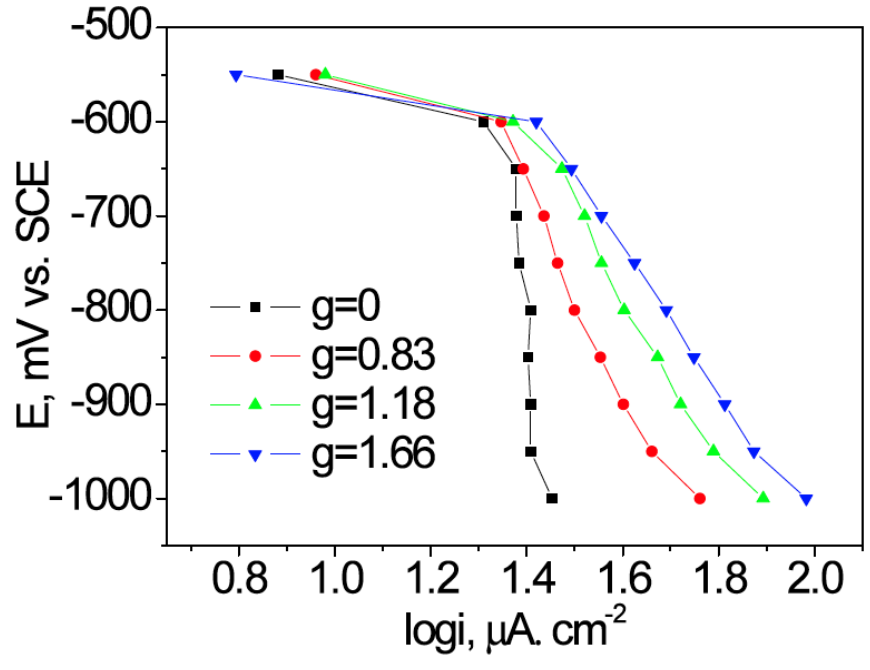

Fig. (8). Cathodic polarization curves of a vertical metal plate electrode under partial immersion in $0.1 \mathrm{M} \mathrm{NaCl}$ solution as a function of $g$ [5].

It was clearly observed that, when the value of $g$ was greater than 0.8 , the cathodic polarization curves were deviated from the standard limiting diffusion control curves, which is attributed to the contribution of TPB width to the cathodic polarization curves. That is, an increase of cathodic polarization potential leads to an increase of TPB width (as Fig. 7) due to the electrocapillary action at TPB zone. The increase in $\mathrm{w}$ broadens the TPB zone, leading to an increase of cathodic limiting current density with increasing the cathodic polarization potential (as Fig. 8). By combining Fig. (8) with Fig. (7), the cathodic limiting current density plotted against $w$ instead of $E$ is shown in Fig. (9). It is observed that the cathodic limiting current densities linearly increased with increasing the TPB width, indicating the important influence of TPB width on cathodic oxygen reduction process. The linear equations fitted from Fig. (7) are listed in Table 2. A simple estimation based on Table 2 reveals that when $\mathrm{w}$ increases twice, $i_{d}$ increases nearly 0.5 times, confirming the significant influence of TPB width on cathodic process of metals. In addition, the greater the value of $g$, the larger the slope of the equation is, indicating the effect of TPB length on the cathodic oxygen reduction process.

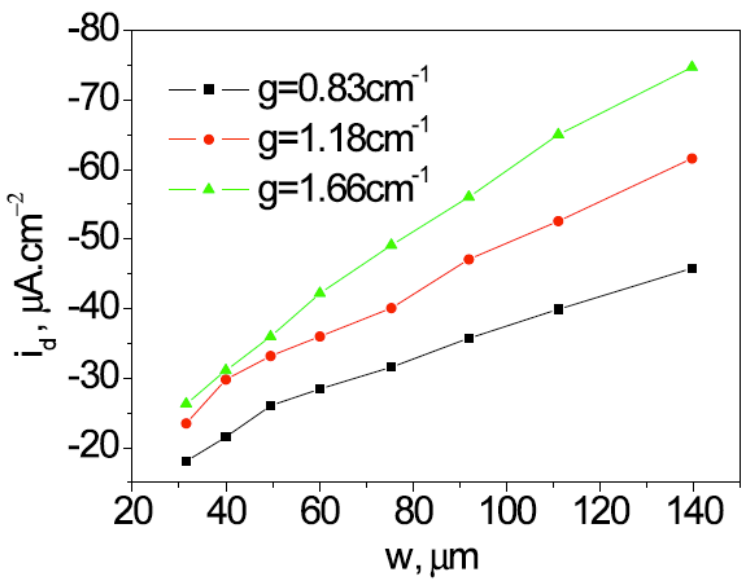

Fig. (9). Plots of cathodic limiting current densities as a function of TPB width obtained by combining Fig. (7) with Fig. (8).
Table 2. The Linear Fitting Equations Derived from Fig. (7)

\begin{tabular}{|c|c|}
\hline $\boldsymbol{g} / \mathbf{c m}^{-1}$ & Linear Fitting Equation \\
\hline \hline 0.83 & $i_{d}\left(\mu \mathrm{A} \cdot \mathrm{cm}^{-2}\right)=-12.3-0.25^{*} w(\mu \mathrm{m})$ \\
\hline 1.18 & $i_{d}\left(\mu \mathrm{A} \cdot \mathrm{cm}^{-2}\right)=-15.3-0.34^{*} w(\mu \mathrm{m})$ \\
\hline 1.66 & $i_{d}\left(\mu \mathrm{A} \cdot \mathrm{cm}^{-2}\right)=-13.7-0.45^{*} w(\mu \mathrm{m})$ \\
\hline
\end{tabular}

The cathodic polarization curves of a partially immersed post-tilt electrode at different electrode-tilt angles can also be used to evaluate the effect of TPB width on cathodic oxygen reduction process of metals. Note that the TPB width can be obtained by measuring contact angles at different electrodetilt angles. Fig. (10) shows the cathodic limiting current densities of a post-tilt A3 carbon steel electrode under partial immersion in $0.1 \mathrm{M} \mathrm{NaCl}$ solution taken at $-900 \mathrm{mV}$ as a function of w. A similar linear relationship between the cathodic limiting current density and the TPB width was observed, in good agreement with the tendency in Fig. (9), confirming that the dependence of cathodic process of metals on the TPB width.

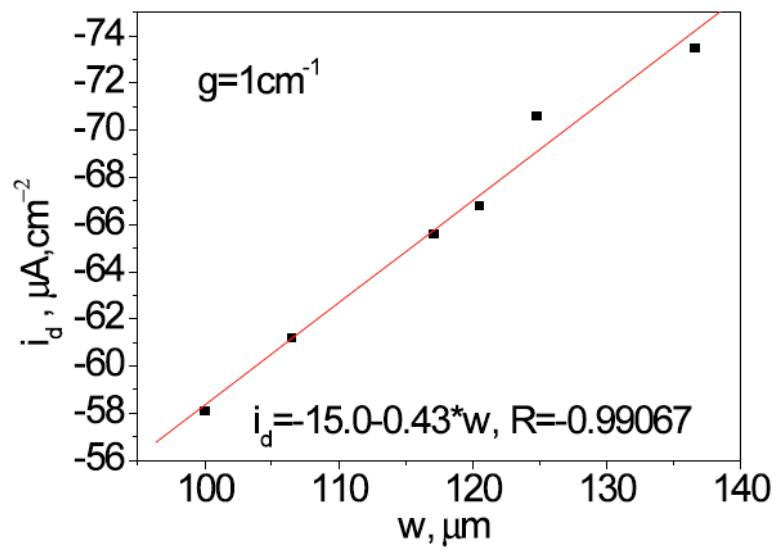

Fig. (10). Plot of cathodic limiting current densities as a function of TPB width for a post-tilt A3 carbon steel electrode under partial immersion in $0.1 \mathrm{M} \mathrm{NaCl}$ solution.

As described in the paper [4], the electrochemical reaction zone under the liquid layer can be divided into a bulk zone and a TPB zone, and the total cathodic limiting current flows through these two zones, i.e.

$I_{d}=I_{b u l k}+I_{3 B}$

It is known that the TPB zone is a high-speed cathodic reaction zone, the current density in which is 2 times greater than that in bulk solution [4], thus change in the area of TPB zone has a significant influence on the total cathodic limiting current $\left(\mathrm{I}_{\mathrm{d}}\right)$. That is, an increase of TPB zone area will lead to a significant increase of the total cathodic limiting current, and then lead to a significant increase of its current density $\left(i_{d}\right)$ since the area change of TPB zone has little effect on the total electrochemical reaction zone. Note that the area of TPB zone is proportional to the TPB length and width, thus the increase of $i_{d}$ will be caused by the increase of TPB width. In addition, the greater the value of $g$ (TPB length per unit area), the higher the degree of area increase of TPB zone with an increase in $\mathrm{w}$, leading to the result that the increased 
degree of $i_{d}$ (corresponding to the slope of curves in Fig. 9) increases with increasing the value of $\mathrm{g}$, in consistent with the fitting results in Table 2.

\subsection{Effect of TPB Width on Corrosion Process of Metals}

The electrochemical characteristics of corrosion of metals under partial immersion in electrolyte were studied by electrochemical impedance spectroscopy (EIS) and linear polarization resistance (LPR) technique.

Fig. (11) shows the Nyquist diagrams of a partially immersed post-tilt $\mathrm{A} 3$ steel electrode in $0.1 \mathrm{M} \mathrm{NaCl}$ solution as a function of w. It was observed that the Nyquist diagrams in all cases exhibited capacitive semicircles and no distinct diffusion behavior was observed in the low frequency region. Taking into account that the electrode process has not changed with the TPB width, the corrosion behavior of A3 carbon steel is still under a mixed diffusion and charge transfer process control, and the corresponding equivalent circuit is shown in Fig. (12), where $\mathrm{R}_{\mathrm{s}}$ is the solution resistance, $C_{d l}$ the double layer capacitance, $R_{p}$ the polarization resistance and $\mathrm{W}$ the Warburg impedance. The polarization resistance $R_{p}$ has been widely accepted as a very useful parameter for evaluating the corrosion rate of metals.

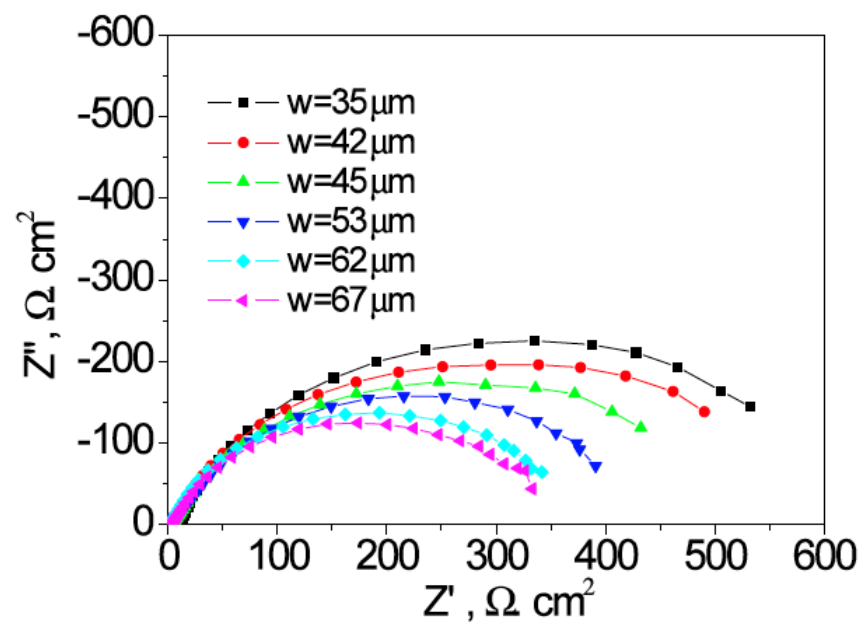

Fig. (11). Experimental Nyquist diagrams as a function of $w$ for a post-tilt $\mathrm{A} 3$ steel electrode under partial immersion in $0.1 \mathrm{M} \mathrm{NaCl}$ solution, in which Z' and Z" refer to real part impedance and image part impedance, respectively.

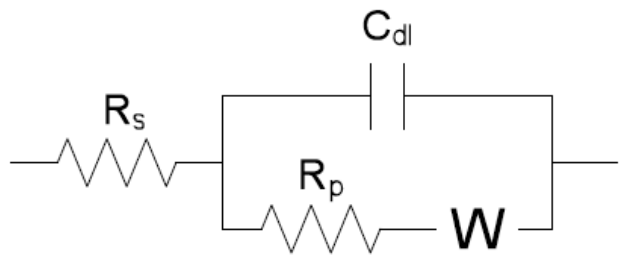

Fig. (12). Equivalent circuit representing the corrosion process of Fig. (9), in which $R_{s}$ is the solution resistance, $C_{d l}$ is the double layer capacitance, $R_{p}$ is the polarization resistance and $W$ is the Warburg impedance [5].

The values of $R_{p}$ in Fig. (12) calculated to Fig. (11), which decreases with increasing the TPB width, indicating that the corrosion rates of A3 carbon steel are strongly dependent on the TPB width. The accurate corrosion rate $\left(\mathrm{i}_{\text {corr }}\right)$ can be calculated by Stern-Geary formula. $i_{\text {corr }}=B / R_{p}$

where $\mathrm{B}$ is the proportional constant value and the value range is about $17 \mathrm{mV}-21 \mathrm{mV}$. Assuming that $\mathrm{B}=19 \mathrm{mV}$, the calculated values of corrosion rate as a function of $\mathrm{w}$ is shown in Fig. (13).

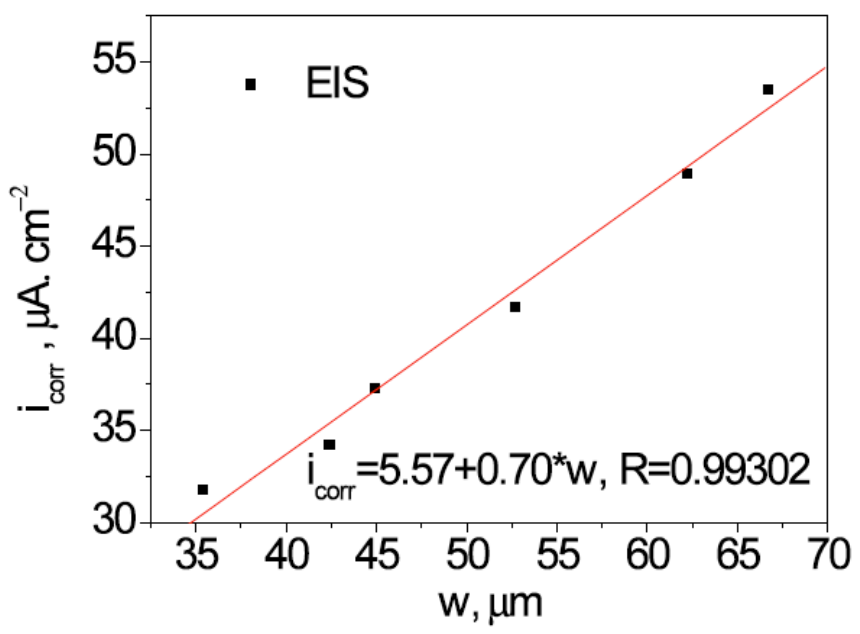

Fig. (13). Corrosion rate of a partially immersed post-tilt A3 steel electrode in $0.1 \mathrm{M} \mathrm{NaCl}$ solution as a function of $w$.

It was observed that the corrosion rate linearly increased with increasing the TPB width, showing a similar tendency as that of the cathodic limiting current density (as Figs.9, 10). This result indicates that the corrosion of smooth $A 3$ steel must be under the control of cathodic oxygen reduction process. A simple estimation, based on the linear fitting equation in Fig. (13), reveals that the corrosion rate increases nearly 0.86 times when $\mathrm{w}$ increases twice, confirming the significant influence of TPB width on corrosion rate of metals.

The linear polarization resistance (LPR) technique has been widely accepted as a very useful method for monitoring corrosion rate of metals. Fig. (14) shows the linear polarization curves of a partially immersed post-tilt A3 steel electrode in $0.1 \mathrm{M} \mathrm{NaCl}$ solution as a function of w. From

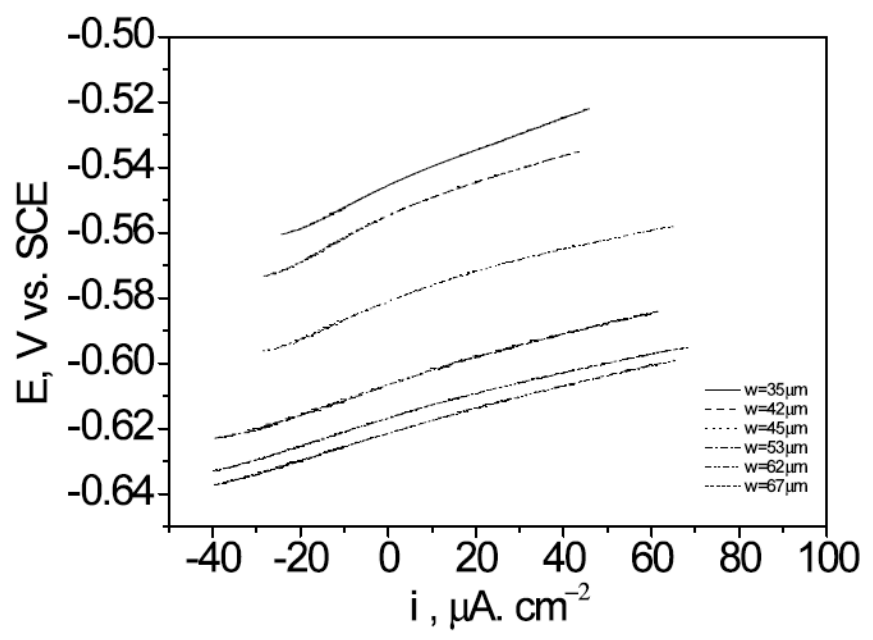

Fig. (14). Linear polarization curves of a partially immersed posttilt $\mathrm{A} 3$ steel electrode in $0.1 \mathrm{M} \mathrm{NaCl}$ solution as a function of $w$. 
Fig. (14) we can see that, all curves show a similar linear behavior, indicating that the corrosion mechanisms of A3 carbon steel under different TPB width were similar with each other. Linear polarization resistance $R_{p}$ was calculated from the slope of LPR curves. The comparisons of $R_{p}$ or $1 / R_{p}$ derived from EIS and LPR curves as a function of $w$ were shown in Fig. (15). It is found that two kinds of test results (EIS and LPR curve) have very good correlation, further confirming the dependence of corrosion process of metals on the TPB width.

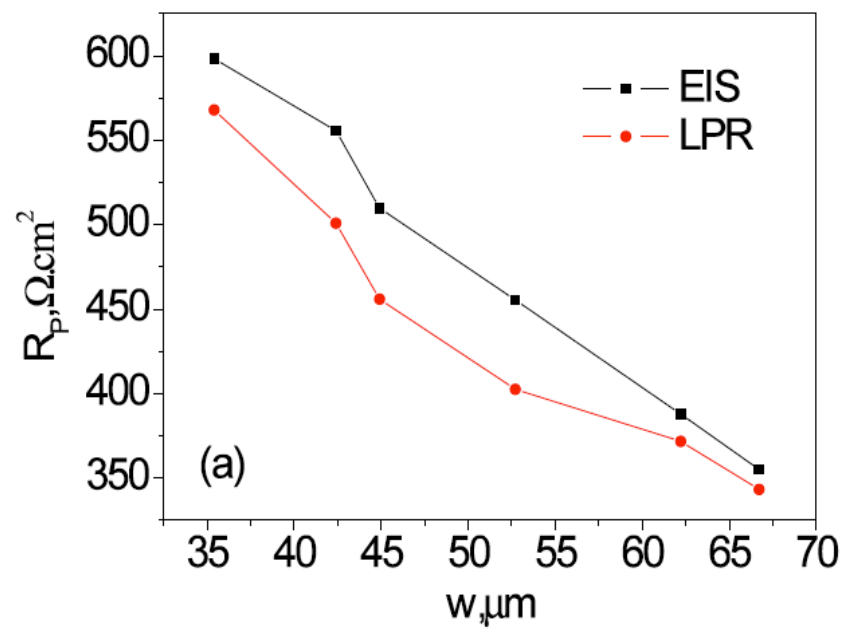

the average thickness of water film $\bar{\delta}$ is about $50 \mu \mathrm{m}$. Substituting $\mathrm{w}^{2}=550 \mu \mathrm{m}$ and $\bar{\delta}=50 \mu \mathrm{m}$ into Eq. (4), we get const $=0.0275 \mathrm{~mm}^{2}$. Then Eq. (4) can be rewritten as

$\bar{\delta}=\frac{0.0275 \mathrm{~mm}^{2}}{w}$

Based on Eq. (7), the average thickness of water film can be roughly evaluated by TPB width. When $\mathrm{w}$ increases twice, $\bar{\delta}$ reduces by $50 \%$. As evaluated from Fig. (11), when

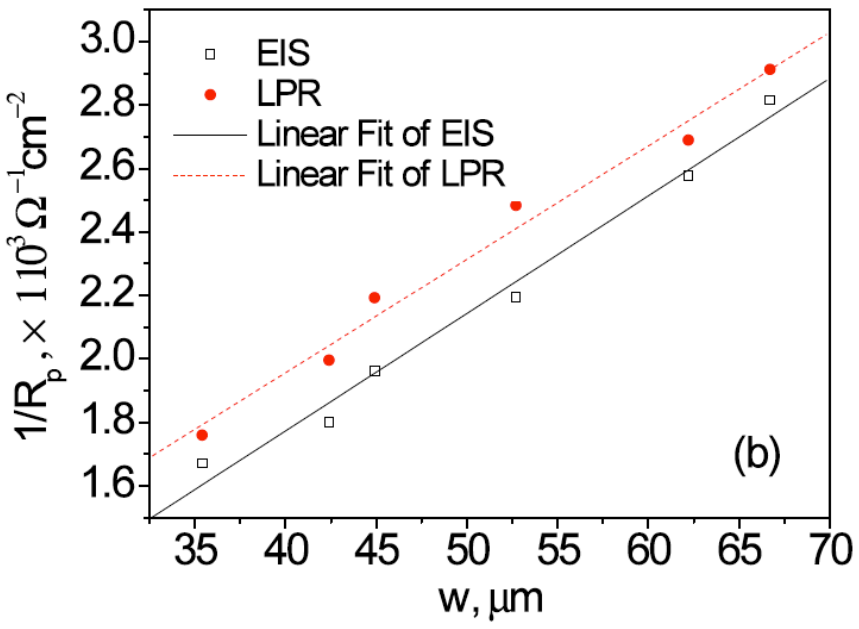

Fig. (15). Comparison of $R_{p}$ and $1 / R_{p}$ obtained from between EIS and LPR as a function of $w$. (a) $R_{p}$; (b) $1 / R_{p}$.

\subsection{Evaluation of Water Film Thickness Effects on Atmospheric Corrosion Rate by TPB Width}

In the initial stage of atmospheric corrosion, water film thickness is an important property of liquid state responsible for the atmospheric corrosion rate. The water film thickness affects corrosion rate mainly by influencing the TPB width. The thinner the average thickness of water film, the greater the value of TPB width. Thus we can consider that the average thickness of water film is inversely proportional to the TPB width, given by

$\bar{\delta}=\frac{\text { const }}{w}$

where const is a constant.

Assuming that water film on metal surface exists in the form of droplet in the shape of spherical cap (as Fig. 16), the maximum thickness of droplet $\left(\delta_{\max }\right)$ can be expressed as

$\delta_{\max }=r\left(\frac{1-\cos \theta}{\sin \theta}\right)=r \cdot \operatorname{tg} \frac{\theta}{2}$

where $r$ is the droplet radius and $\theta$ is the contact angle.

Assume that $\delta_{\max }=100 \mu \mathrm{m}$, then the TPB zone covers the whole liquid region. On this condition, TPB width can be given as

$w=2 r=2 \delta_{\text {max }} \cdot \operatorname{ctg} \frac{\theta}{2}$

Substituting $\delta_{\max }=100 \mu \mathrm{m}$ and $\theta=40^{\circ}$ (measured value at $900 \mathrm{mV} / \mathrm{SCE}$ ) into Eq. (6), we get $\mathrm{w}=550 \mu \mathrm{m}$. Assume that $\mathrm{w}$ increases twice, the corrosion rate increases nearly 0.86 times, meaning that on condition of $\bar{\delta}>20 \mu \mathrm{m}$, at which the maximum oxygen reduction rate was reached [2], the corrosion rate increases nearly 0.86 times when $\bar{\delta}$ reduces by $50 \%$.

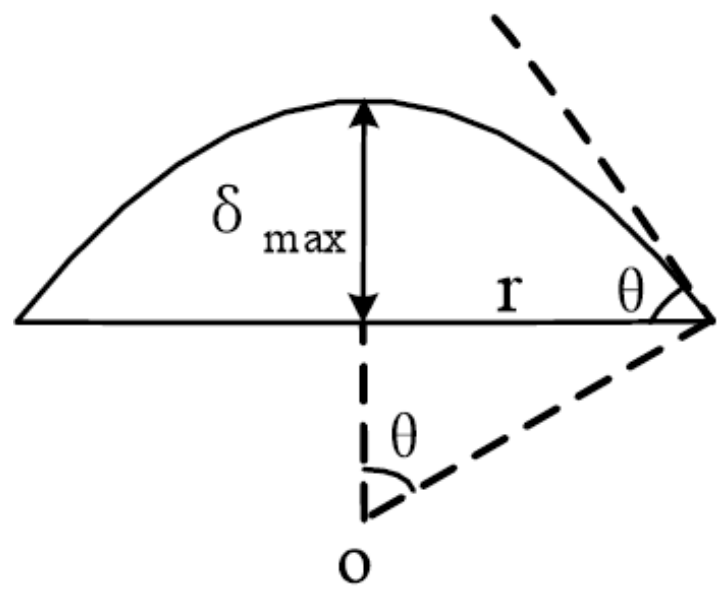

Fig. (16). The geometry of droplet attached on planar electrode surface [12].

Based on above discussion, the effect of water film thickness on atmospheric corrosion rate can be quantitatively evaluated by the TPB width. This evaluation may replace the complex electrochemical measurement of corrosion rates under thin water film, thus have important implications in the studies of corrosion behavior of metals in atmospheric environment. 


\section{CONCLUSION}

Based on our previous work on the effects of TPB length on atmospheric corrosion [4-12], the effect of TPB width of water film on metal surfaces was also studied for evaluating the roles of dispersed water film on atmospheric corrosion process.

It was found out that the TPB width not only varied with the tilted angle of metal surface with water surface but also varied with the potential applied on the metal. A decrease of contact angles with a negative shift of potential reveals that the TPB width linearly increases with increasing the cathodic polarization potential which may relate to spreading of micro-droplets. In addition. Therefore, the cathodic limiting current density and corrosion current density linearly increased with increasing the TPB width, and the corrosion rate increases nearly 0.86 times when width $\mathrm{w}$ increases twice, confirming the significant influence of TPB width on cathode and corrosion behavior. Based on above discussion, the effect of water film thickness on atmospheric corrosion behavior can be quantitatively evaluated by the TPB width.

\section{ACKNOWLEDGEMENT}

The authors gratefully acknowledge the help rendered by the National Natural Science Foundation of China under Contact 50971118.

\section{REFERENCES}

[1] Tsuru T, Nishikata A, Wang Jia. Electrochemical studies on corrosion under water film. Mater Sci Eng 1995; A198: 161-7.
[2] Wang J, Tsuru T. An investigation on oxygen reduction under thin electrolyte layer using Kelvin probe reference electrode. J Chin Soc Corrosion Protec 1995; 15: 180-5.

[3] Wang J, Tsuru T. Electrochemical measurements under thin electrolyte layer using Kelvin prob reference electrode. J Chin Soc Corrosion Protec 1995; 15: 173-9.

[4] Jiang J, Wang J, Lu Y, Hu J. Effect of length of gas/liquid /solid three-phase boundary zone on cathodic and corrosion behavior of metals. Electrochim Acta 2009; 54: 1426-5.

[5] Wang J, Tsuru T. Potential distribution and micro-droplets formation on the metal with salt particle deposition. The 204th Meeting of the Electrochem Soc, The Electrochem Soc Inc; Orlando 2003; D2: 472.

[6] Zhang J, Wang Jia, Wang Yanhua. Electrochemical investigations of micro-droplets formed on metals during the deliquescence of salt particles in atmosphere. Electrochem Commun 2005; 7: 443-8.

[7] Zhang J, Wang J, Wang Y. Phenomenon of micro-droplets formation on metals during the deliquescence of salt particles in atmosphere. Acta Physico-Chim Sin 2005; 21: 993-6.

[8] Zhang J, Wang J, Wang Y. Micro-droplets formation during the deliquescence of salt particles in atmosphere. Corrosion 2005; 61: $1167-72$.

[9] Liang LH, Jiang YL, Wang J. Effects of property of primary droplet on micro-droplet formation. Chem J Chin Univ 2006; 27 : 2148-51.

[10] Zhang JB, Wang YH, Jiang YL, Wang J. Micro-droplet phenomenon and atmospheric corrosion- I. Formation and spreading of micro - droplets. J Chin Soc Corrosion Protec 2006; 26: $207-10$.

[11] Zhang JB, Wang YH, Jiang YL, Wang J. Micro-droplet phenomenon and atmospheric corrosion-II. Electrochemical characteristics of the micro-droplets phenomenon. J Chin Soc Corrosion Protec 2006; 26: 282-5.

[12] Jiang J, Wang J, Wang W, Zhang W. Modeling influence of gas/ liquid/solid three-phase boundary zone on cathodic process of soil corrosion. Electrochim Acta 2009; 54: 3623-9. 